\title{
Desempenho e características das carcaças de novilhos superprecoces em pastos hibernais submetidos a intensidades de pastejo
}

\author{
Lemar Maciel da Rocha(1), Paulo César de Faccio Carvalho(1), Carolina Baggio(1), Ibanor Anghinoni(1), \\ Marília Lazzarotto Terra Lopes ${ }^{(1)}$, Stefani Macari(1) e Jamir Luis Silva da Silva(2)
}

\begin{abstract}
(1)Universidade Federal do Rio Grande do Sul, Avenida Bento Gonçalves, o⒎712, CEP 91540-000 Porto Alegre, RS. E-mail: lemrocha@hotmail.com, paulocfc@ufrgs.br, cbaggio4@hotmail.com, ibanghi@ufrgs.br, mterralopes@hotmail.com, stefanimacari@yahoo.com.br (2)Embrapa Clima Temperado, BR 392, Km 78, Caixa Postal 403, CEP 96001-970 Pelotas, RS. Pelotas. E-mail: jamir.silva@cpact.embrapa.br
\end{abstract}

Resumo - O objetivo deste trabalho foi avaliar os efeitos de intensidades de pastejo na terminação de novilhos superprecoces, em pastagens de inverno em sucessão à soja. Foram avaliadas diferentes alturas de pré-pastejo de pastos mistos de azevém e aveia: 10, 20, 30 e $40 \mathrm{~cm}$. Empregou-se o delineamento de blocos ao acaso, com três repetições. Foram utilizados machos mestiços de raças de corte, inteiros, com idade de 10 meses e peso médio inicial de $192 \pm 12 \mathrm{~kg}$. As seguintes variáveis foram avaliadas: massa e oferta de forragem, altura do pasto, taxa de acúmulo diário e acúmulo total de forragem, ganho de peso médio diário (GMD), carga animal e ganho de peso vivo por unidade de área (GPA), além de características qualitativas de carcaça. Os novilhos foram abatidos aos 14 meses de idade. O GMD ajustou-se a um modelo de regressão quadrático e teve o ponto de máximo desempenho entre 20 e $25 \mathrm{~cm}$ de altura de pré-pastejo, enquanto o GPA ajustou-se a um modelo linear negativo. A qualidade da carcaça dos novilhos foi satisfatória, quando os pastos foram manejados em alturas superiores a $10 \mathrm{~cm}$. É possível produzir carcaças de novilhos superprecoces, na fase de pastagem de sistemas integrados de produção, durante o inverno, em sucessão à soja. O manejo de pastos mistos de azevém e aveia, em alturas entre 20 e $25 \mathrm{~cm}$, otimiza o desempenho animal individual e por área.

Termos para indexação: carga animal, ganho de peso médio diário, ganho de peso por unidade de área, integração lavoura-pecuária, oferta de forragem.

\section{Performance and carcass characteristics of yearling bulls on winter pastures subjected to grazing intensities}

\begin{abstract}
The objective of this work was to assess the grazing intensity effects on the finishing of yearling bulls, in winter pastures in succession to soybean crop. Sward pre-grazing different heights of mixed pasture between ryegrass and oat were evaluated: $10,20,30$ and $40 \mathrm{~cm}$. A randomized complete block design was utilized with three replicates. Ten-month-old beef crossbred bulls were used, with initial live weight of $192 \pm 12 \mathrm{~kg}$. The following variables were evaluated: forage mass and allowance, sward height, forage daily accumulation rate and forage total accumulation, average daily weight gain (ADG), stocking rate and weight gain per unit area (GA), as well as the qualitative characteristics of the carcasses. The yearling bulls were slaughtered at 14 months of age. ADG fitted a quadratic model, with maximum performance between 20 and $25-\mathrm{cm}$ sward height, while GA fitted a negative linear model. Yearling bulls showed a satisfactory carcass quality when pastures were managed with pre-grazing heights higher than $10 \mathrm{~cm}$. It is possible to finish yearling bulls in the pasture phase of integrated production systems, during winter, in succession to soybean crop. The management of ryegrass and oat mixed pastures at sward pre-grazing heights of 20 and $25 \mathrm{~cm}$ optimize individual animal performance and per area unit.
\end{abstract}

Index terms: stocking rate, average daily weight gain, weight gain per unit area, crop-livestock integration, forage allowance.

\section{Introdução}

O Brasil possui 163,9 milhões de bovinos de corte, dos quais cerca de 11,4 milhões encontram-se no Rio Grande do Sul (RS) (Anualpec, 2006). A maior parte desses animais, no RS, é criada nos campos nativos, que têm como principal característica a heterogeneidade temporal e espacial na oferta de forragem (Poli \& Carvalho, 2001). O baixo valor nutritivo dessas pastagens, associado ao nível reduzido de oferta de forragem durante os meses de outono-inverno, afeta o desempenho dos bovinos sob pastejo (Fontoura Júnior et al., 2007).

Pastagens cultivadas na estação fria podem possibilitar a terminação de novilhos (Lopes et al.,

Pesq. agropec. bras., Brasília, v.46, n.10, p.1379-1384, out. 2011 
2008), o que representaria uma oportunidade para o aumento da rentabilidade das propriedades agrícolas. Somente $18 \%$ dos 6,4 milhões de hectares cultivados anualmente com soja e milho, durante a safra de verão no Rio Grande do Sul, são utilizados para plantio de trigo, aveia-branca, cevada e centeio no inverno. $\mathrm{O}$ restante dessa área permanece praticamente sem proporcionar renda, com culturas para cobertura de solo ou em pousio. A exploração de pastagens de inverno proporciona produção de forragem durante um período crítico de oferta, o que a torna estratégica para produção a animal nessa época. Assim, estudos de sistemas que viabilizem ciclos pecuários curtos, que se adequem ao interstício de cultivos de verão, são importantes.

Em sistemas integrados é importante manejar o pasto de forma que se permita a obtenção de boa produção por animal e por unidade de área sem, contudo, prejudicar a lavoura de grãos subsequente (Carvalho et al., 2010). Além disso, em razão do período relativamente curto para a exploração de pastagens em sistemas integrados, a terminação de novilhos precoces ou superprecoces pode ser uma boa alternativa, tendose em vista a possibilidade de maior retorno financeiro. Contudo, deve-se levar em consideração que os valores de peso e participação percentual dos cortes comerciais na carcaça são características de interesse dos frigoríficos, na avaliação do valor do produto adquirido, o que torna interessante a quantificação dessas respostas aos sistemas de cultivo.

O objetivo deste trabalho foi avaliar o efeito de intensidades de pastejo na terminação de novilhos superprecoces, em pastagens de inverno em sucessão à soja.

\section{Material e Métodos}

O experimento foi realizado no ano de 2005, na Fazenda Espinilho, no Município de São Miguel das Missões, RS. O solo da região é classificado como Latossolo Vermelho distroférrico, com textura muito argilosa. Segundo a classificação de Köppen, o clima é do tipo $\mathrm{Cfa}$, subtropical úmido. A área experimental utilizada vinha sendo cultivada há 13 anos sob semeadura direta de soja, com utilização de animais em pastejo durante o inverno, desde o ano 2000.

Em 4/5/2005, a pastagem de inverno, constituída de mistura entre aveia-preta (Avena strigosa Schreb.) e azevém (Lolium multiflorum Lam.), foi implantada em sucessão à lavoura de soja, por meio de semeadura direta, com $100 \mathrm{~kg} \mathrm{ha}^{-1}$ de semente de aveia-preta e $25 \mathrm{~kg} \mathrm{ha}^{-1}$ de azevém. A adubação de base foi de $300 \mathrm{~kg} \mathrm{ha}^{-1}$ de superfosfato simples. Em 8/6/2005, aplicou-se nitrogênio em cobertura, na dose de $45 \mathrm{~kg} \mathrm{ha}^{-1}$ na forma de ureia. Os animais iniciaram o pastejo na área no dia 5 de julho, momento em que o pasto atingiu $19,1 \pm 1,6 \mathrm{~cm}$ de altura média, o que representou $901 \pm 33 \mathrm{~kg} \mathrm{ha}^{-1}$ de massa de matéria seca (MS). O pastejo estendeu-se até 13 de novembro, quando os animais foram abatidos.

A área do experimento foi subdividida em 12 unidades experimentais (de 0,8 a 3,6 ha), no total de 21,5 ha. Foram avaliados quatro tratamentos de intensidade de pastejo, representados por diferentes alturas de pré-pastejo: 10, 20, 30 e $40 \mathrm{~cm}$. As alturas de pré-pastejo foram manejadas a partir da utilização de cargas animais variáveis. As unidades experimentais foram dispostas segundo o delineamento de blocos completos ao acaso, com três repetições.

Foram utilizados machos mestiços de raças de corte, inteiros, de aproximadamente dez meses de idade, com peso médio inicial de $192 \pm 12 \mathrm{~kg}$. No início do experimento, os animais foram pesados após jejum prévio de 12 horas. O pastejo foi realizado de acordo com o método de lotação contínua, com taxa de lotação variável. Foram utilizados três animais teste por unidade experimental. Os animais reguladores entravam e saiam dos pastos, conforme a altura variasse em relação à meta de manejo estipulada, com uso da técnica "put-and-take" descrita por Mott \& Lucas (1952).

A altura real dos pastos foi medida com bastão graduado denominado "sward stick", a exemplo de Aguinaga et al. (2006). O controle da altura dos pastos foi feito a intervalos de 15 dias, aproximadamente, no total de nove avaliações. A leitura era feita em 100 pontos por unidade experimental, em caminhamento aleatório, a fim de se mensurar a altura média da pastagem. O valor médio das medições de cada unidade foi utilizado como variável independente, em equações de regressão linear com o valor de massa de forragem real dos pastos. A massa de forragem foi avaliada a cada 28 dias, aproximadamente, em cinco pontos por unidade experimental, com um quadrado de $0,25 \mathrm{~m}^{2}$. Para determinação da taxa de acúmulo diária de MS, realizada a cada 28 dias, aproximadamente, 
foram utilizadas três gaiolas de exclusão de pastejo por unidade experimental, pela técnica do triplo emparelhamento, conforme descrito em Fontoura Júnior et al. (2007). A oferta de forragem por unidade experimental foi calculada com a divisão da massa de forragem pelo número de dias em pastejo, e o resultado foi somado à taxa de acúmulo diária de MS correspondente. $\mathrm{O}$ valor obtido foi multiplicado por 100 e dividido pela carga animal. Também foi calculado o acúmulo total de forragem, por meio da multiplicação do acúmulo diário de forragem pelo número total de dias, somado à massa de forragem inicial.

Para avaliar o desempenho animal, foram feitas três pesagens, com jejuns prévios de 12 horas. O ganho médio diário foi calculado pela diferença entre peso final e inicial dos animais teste, dividido pelo número de dias do período. A carga animal média, expressa em quilogramas de peso vivo (PV) por hectare por dia, foi calculada pelo somatório do peso médio dos animais teste com o peso médio de cada animal regulador, tendo-se multiplicado o resultado pelo número de dias em que os animais permaneceram no pasto, e dividido pelo número total de dias de pastejo. $\mathrm{O}$ ganho de peso vivo por hectare foi obtido pela multiplicação da taxa média de lotação (número de animais por dia) pelo ganho médio diário dos animais teste.

O escore de condição corporal dos novilhos foi atribuído nas pesagens inicial e final por meio de observação visual, conforme Lowman et al. (1973), numa escala de 1,0 (muito magro) a 5,0 (muito gordo). Os animais foram abatidos no dia 15/11/2005. Os resultados apresentados referem-se ao valor médio obtido do abate de nove animais teste de cada tratamento.

Após o abate, as carcaças foram avaliadas em relação à sua conformação e espessura de gordura subcutânea. As carcaças foram identificadas, lavadas, pesadas para obtenção do peso de carcaça quente e, em seguida, resfriadas a $-2^{\circ} \mathrm{C}$ por 24 horas. Após esse tempo, as carcaças foram novamente pesadas para determinação dos parâmetros: peso da carcaça fria, peso de dianteiro, peso de traseiro e peso de costela.

Os dados foram submetidos à análise de variância, a 5\% de probabilidade, e à análise de regressão. Para a espessura de gordura subcutânea, foi realizada a análise de variância e o teste de Tukey, a 5\% de probabilidade. As análises foram realizadas com uso do SAS (SAS Institute, 1997).

\section{Resultados e Discussão}

A altura real do pasto, a massa de forragem e a oferta de forragem variaram de acordo com as intensidades de pastejo, todas ajustadas a modelos lineares (Tabela 1). No entanto, a taxa de acúmulo diária e acúmulo total de forragem não foram influenciadas pelos tratamentos, e apresentaram médias de $55,8 \mathrm{~kg} \mathrm{ha}^{-1}$ por dia e $8.210 \mathrm{~kg} \mathrm{ha}^{-1} \mathrm{de} \mathrm{MS}$, respectivamente. Esses resultados estão dentro da amplitude observada em experimento análogo, por Aguinaga et al. (2006).

$\mathrm{O}$ ganho de peso diário diminuiu de forma linear com o incremento na altura pré-pastejo (Figura 1), o que está de acordo com Flores et al. (2008). A altura pré-pastejo afeta tanto as características verticais do dossel como as horizontais, e essas características interferem diretamente no consumo de forragem, que é a principal determinante do desempenho animal (Carvalho et al., 2007). Observou-se incremento no ganho de peso diário até aproximadamente $25 \mathrm{~cm}$, com posterior queda. Os valores de ganho de peso diário, para as alturas pré-pastejo de 10 e $20 \mathrm{~cm}$, foram de 0,96 e 1,2 $\mathrm{kg}$ por animal por dia de PV, respectivamente. Ganhos semelhantes foram relatados por Aguinaga et al. (2006), que observaram valores de

Tabela 1. Altura real do pasto, massa de forragem, oferta de forragem, taxa de acúmulo diária e acúmulo total de forragem de pastos mistos de aveia e azevém submetidos a diferentes intensidades de pastejo, representadas por quatro metas de alturas de pré-pastejo.

\begin{tabular}{|c|c|c|c|c|c|c|c|}
\hline \multirow[t]{2}{*}{ Característica } & \multicolumn{4}{|c|}{ Altura pré-pastejo $(\mathrm{cm})$} & \multirow[t]{2}{*}{ Erro-padrão } & \multirow[t]{2}{*}{ Regressão } & \multirow[t]{2}{*}{$\mathrm{R}^{2}$} \\
\hline & 10 & 20 & 30 & 40 & & & \\
\hline Altura real $(\mathrm{cm})$ & 12,1 & 23,4 & 29,3 & 36,1 & 1,9 & $\hat{\mathrm{Y}}=4,5+0,8 \mathrm{x}$ & $0,99 * *$ \\
\hline Massa de forragem $\left(\mathrm{kg} \mathrm{ha}^{-1}\right)$ & $1.717,7$ & $2.820,3$ & $3.429,3$ & $4.059,0$ & 187,9 & $\hat{\mathrm{Y}}=533,9+98,1 \mathrm{x}$ & $0,99 * *$ \\
\hline Oferta de forragem $(\%)$ & 6,6 & 9,0 & 13,8 & 19,1 & 1,0 & $\hat{\mathrm{Y}}=-1,54+0,56 \mathrm{x}$ & $0,88 * *$ \\
\hline Taxa de acúmulo ( $\mathrm{kg} \mathrm{ha}^{-1}$ por dia) & 63,7 & 48,5 & 58,8 & 52,0 & 7,4 & - & ns \\
\hline Acúmulo total $\left(\mathrm{kg} \mathrm{ha}^{-1}\right)$ & $9.212,7$ & $7.266,7$ & $8.601,3$ & $7.758,3$ & 947,1 & - & ns \\
\hline
\end{tabular}

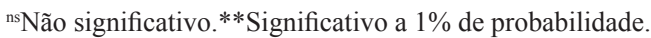


0,73 e $1,14 \mathrm{~kg}$ por animal por dia, em pastos manejados a 10 e $30 \mathrm{~cm}$, respectivamente. Lustosa (1998) registrou $1,18 \mathrm{~kg}$ por animal por dia, em pastagem similar, com oferta diária de forragem de $15 \%$ do PV. A mudança no ganho de peso diário ocorrida a partir de $30 \mathrm{~cm}$, provavelmente, foi decorrência de alterações negativas na estrutura do dossel e, consequentemente, na qualidade do pasto (Lopes et al., 2008).

Embora o tratamento $10 \mathrm{~cm}$ já tenha proporcionado ganho de peso diário satisfatório, ao final do ciclo de utilização, os animais alcançariam, com uso dessa altura pré-pastejo, $34 \mathrm{~kg}$ a menos do que o peso obtido no tratamento com $20 \mathrm{~cm}$. Isso pode representar dificuldades na comercialização do produto, em razão do baixo peso da carcaça. Nesse caso, deve-se levar em conta a vantagem dos tratamentos com ganho de peso diário acima de $1,1 \mathrm{~kg}$, que podem reduzir a necessidade de pastagens de verão para a terminação dos animais.

Observou-se resposta linear negativa do ganho de peso vivo por área às alturas pré-pastejo (Figura 1). No entanto, a resposta clássica normalmente é representada por uma função quadrática (Barbosa et al., 2006). Porém, em ciclos de pastejo curtos, característicos de pastagens anuais de inverno, os modelos lineares têm sido mais frequentemente observados (Aguinaga et al., 2006; Lopes et al., 2008). Como a variação em ganho de peso diário entre os tratamentos foi pequena, o maior ganho de peso vivo por área observado no tratamento $10 \mathrm{~cm}\left(515 \mathrm{~kg} \mathrm{ha}^{-1}\right.$ de PV) ocorreu em razão da maior carga animal utilizada (Figura 2). Cada centrímetro de aumento na altura do pasto correspondeu à redução de $32 \mathrm{~kg} \mathrm{ha}^{-1}$ de PV em carga animal e de $14 \mathrm{~kg} \mathrm{ha}^{-1}$

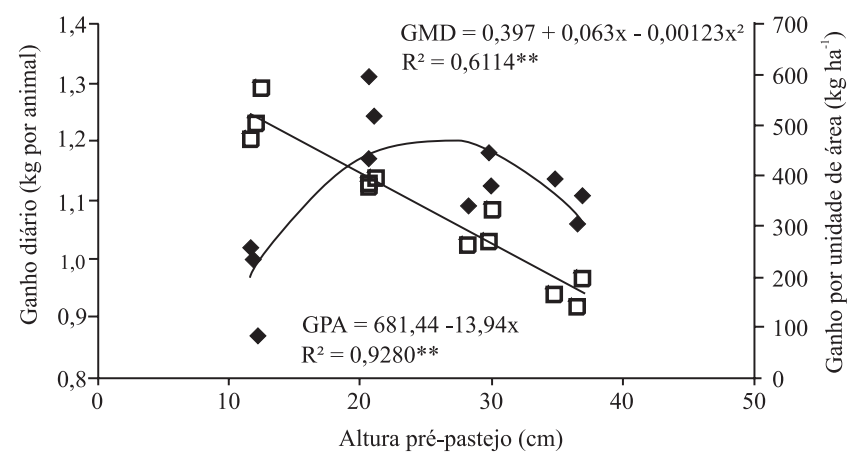

Figura 1. Relação da altura real do pasto, em pré pastejo, com ganho de peso diário (GMD) e ganho de peso vivo por área (GPA) de novilhos de corte, em 131 dias de pastejo em pastos mistos de aveia e azevém. **Significativo a $1 \%$ de probabilidade. em ganho de peso vivo por área. Os valores de carga animal foram inferiores aos reportados por Aguinaga et al. (2006), em consequência dos maiores níveis de nitrogênio empregados pelos autores.

Aguinaga et al. (2006) registraram a necessidade de $17,1 \mathrm{~kg}$ de MS para produzir 1,0 kg de PV, valor próximo ao encontrado no presente trabalho para a altura de 12,1 cm $\left(17,9 \mathrm{~kg} \mathrm{~kg}^{-1}\right)$. Pontes et al. (2004) observaram, em pastagen de azevém manejada com altura semelhante, a necessidade de $26,3 \mathrm{~kg}$ de MS para produzir $1,0 \mathrm{~kg}$ de $\mathrm{PV}$ de cordeiro. Assmann et al. (2004) observaram eficiência de 7,91 kg MS de aveia+azevém+trevo-branco para cada quilograma de $\mathrm{PV}$, o que mostra o alto potencial dessas pastagens de inverno.

O ganho de peso vivo por área diminuiu à medida que a massa de forragem do pasto aumentou (Figura 3). Em relação ao ganho de peso diário, a massa de forragem necessária para ganhos acima de 1,2 kg por animal por dia foi de aproximadamente $3 \mathrm{Mg} \mathrm{ha}^{-1}$ de MS. Esse valor é bem superior ao reportado por Quadros (1999), que relatou serem necessários de 1,2 a 1,5 $\mathrm{Mg} \mathrm{ha}^{-1} \mathrm{de}$ MS, para otimizar o desempenho animal em pastagens de inverno.

Embora elevadas produções por área tenham sido obtidas no tratamento $10 \mathrm{~cm}\left(515 \mathrm{~kg} \mathrm{ha}^{-1} \mathrm{de} \mathrm{PV}\right)$, devese considerar o risco de aumento de impacto negativo nas características físicas do solo (Flores et al., 2007). Além disso, no contexto de integração com áreas de lavoura, deve-se levar em conta que baixas alturas de manejo do pasto resultam em menor massa de forragem $\mathrm{e}$, consequentemente, menor quantidade de palhada para o plantio direto.

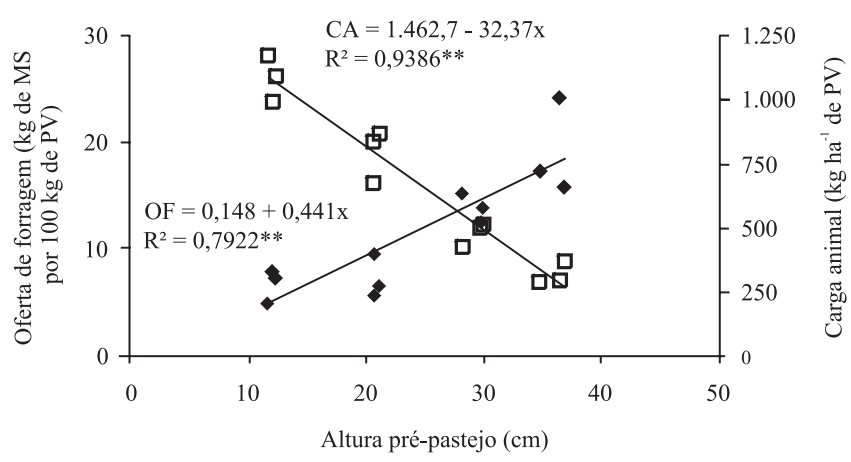

Figura 2. Relação da altura real do pasto, em pré-pastejo, com a oferta de forragem (OF) e a carga animal (CA) de novilhos de corte, em 131 dias de pastejo em pastos mistos de aveia e azevém. **Significativo a $1 \%$ de probabilidade. 
O peso dos animais ao abate não variou com os tratamentos, tendo-se registrado valores de 321, 356,337 e $333 \mathrm{~kg}$ nas alturas 10, 20, 30 e $40 \mathrm{~cm}$, respectivamente. A amplitude de peso ao abate observada está de acordo com os valores reportados por Lopes et al. (2008), que utilizaram a mesma categoria animal e forma de terminação.

O escore médio de condição corporal ao abate foi de 4,1 10,1 e não diferiu entre os tratamentos, assim como a espessura de gordura subcutânea, que apresentou média

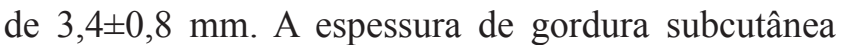
entre 3 e $6 \mathrm{~mm}$ reduz as perdas por desidratação, durante o resfriamento da carcaça, e proporciona maior rendimento e, consequentemente, maior produção de carne. Os animais apresentaram rendimento médio de carcaça de $52 \pm 0,1 \%$. Esse rendimento foi superior ao obtido por Restle \& Vaz (1997), que observaram valor médio de 51,1\%, para novilhos Hereford abatidos aos 14 meses em confinamento. $\mathrm{O}$ peso de carcaça e a espessura de gordura subcutânea, encontrados por esses autores (189,5 $\mathrm{kg}$ e 5,5 mm, respectivamente), foram superiores aos obtidos no presente trabalho.

As diferentes alturas de pasto também não exerceram efeito significativo sobre as características quantitativas das carcaças. Observaram-se valores médios de $177 \pm 8$, $87 \pm 3,24 \pm 1$ e $67 \pm 4 \mathrm{~kg}$ para peso de carcaça fria, peso de traseiro, peso de costela e peso de dianteiro, respectivamente. Uma vez que o mercado exige determinados tamanhos de músculo que compõem esses cortes (Kuss et al., 2005), é de interesse a quantificação dessas respostas. Os resultados observados no presente

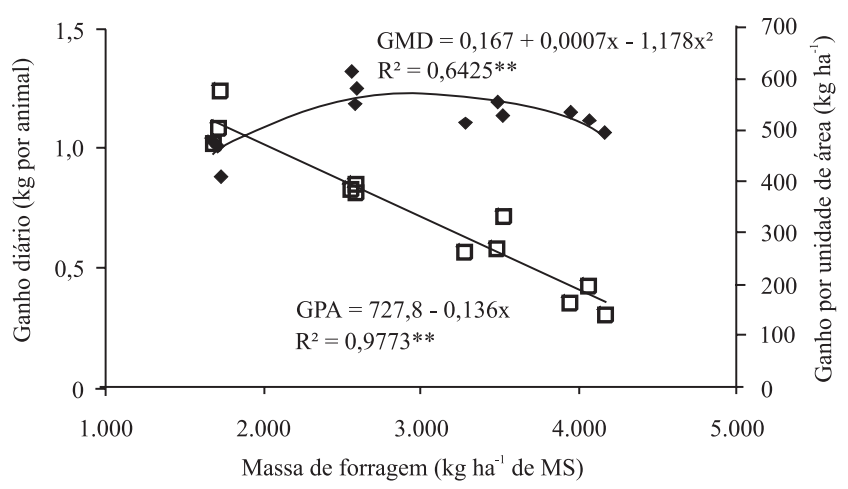

Figura 3. Relação de massa de forragem com ganho de peso diário (GMD) e ganho de peso vivo por área (GPA) de novilhos de corte, em 131 dias de pastejo em pastos mistos de aveia e azevém. ${ }^{* *}$ Significativo a $1 \%$ de probabilidade. trabalho estão de acordo com as características exigidas pelos frigoríficos e pelo mercado consumidor.

Segundo Di Marco (1998), a deposição do ganho de peso de animais em fase de crescimento ocorre nas regiões demaior participação muscular na carcaça, como o traseiro e o dianteiro. Os resultados de percentagem do peso total da carcaça, obtidos no presente trabalho, foram de $49,14,38 \%$, respectivamente, sem que tenha havido diferença significativa entre os tratamentos, muito próximos aos valores encontrados por Restle \& Vaz (1997). É importante ressaltar que as carcaças do presente trabalho foram classificadas como de novilho superprecoce, e satisfizeram ao peso e acabamento exigidos pelos frigoríficos.

\section{Conclusões}

1. O manejo de pastos mistos de azevém e aveia, em alturas entre 20 e $25 \mathrm{~cm}$, otimiza o desempenho animal individual e por unidade de área.

2. A qualidade da carcaça dos novilhos é satisfatória quando os pastos são manejados em alturas superiores a $10 \mathrm{~cm}$.

3. É possível produzir carcaças de novilhos superprecoces, na fase de pastagem de sistemas integrados de produção, durante o inverno, em sucessão à soja.

\section{Referências}

AGUINAGA, A.A.Q.; CARVALHO, P.C. de F.; ANGHINONI, I.; SANTOS, D.T. dos; FREITAS, F.K. de; LOPES, M.T. Produção de novilhos superprecoces em pastagem de aveia e azevém submetida a diferentes alturas de manejo. Revista Brasileira de Zootecnia, v.35, p.1765-1773, 2006.

ANUALPEC. Anuário estatístico da pecuária brasileira. São Paulo: Argos Comunicação, 2006. 370p.

ASSMANN, A.L.; PELISSARI, A.; MORAES, A. de; ASSMANN, T.S.; OLIVEIRA, E.B. de; SANDINI, I. Produção de gado de corte e acúmulo de matéria seca em sistema de integração lavoura-pecuária em presença ou ausência de trevo-branco e nitrogênio. Revista Brasileira de Zootecnia, v.33, p.37-44, 2004.

BARBOSA, M.A.A. de F.; NASCIMENTO JÚNIOR, D. do; CECATO, U. Dinâmica da pastagem e desempenho de novilhos em pastagem de capim-tanzânia sob diferentes ofertas de forragem. Revista Brasileira de Zootecnia, v.35, p.1594-1600, 2006.

CARVALHO, P.C. de F.; ANGHINONI, I.; MORAES, A. de; SOUZA, E.D. de; SULC, R.M.; LANG, C.R.; FLORES, J.P.C.; LOPES, M.L.T.; SILVA, J.L.S. da; CONTE, O.; WESP, C. de L.; LEVIEN, R.; FONTANELI, R.S.; BAYER, C. Managing grazing animals to achieve nutrient cycling and soil improvement in no-till 
integrated systems. Nutrient Cycling in Agroecosystems, v.88, p.259-273, 2010.

CARVALHO, P.C. de F.; KOZLOSKI, G.V.; RIBEIRO FILHO, H.M.N.; REFFATTI, M.V.; GENRO, T.C.M.; EUCLIDES, V.B.P. Avanços metodológicos na determinação do consumo por ruminantes em pastejo. Revista Brasileira de Zootecnia, v.36, p.151-170, 2007.

DI MARCO, O.N. Crecimiento de vacunos para carne. Buenos Aires: Oscar N. Di Marco, 1998. 246p.

FLORES, J.P.C.; ANGHINONI, I.; CASSOL, L.C.; CARVALHO, P.C. de F.; LEITE, J.G. Dal B.; FRAGA, T.I. Atributos físicos do solo e rendimento de soja em sistema plantio direto em integração lavoura-pecuária com diferentes pressões de pastejo. Revista Brasileira de Ciência do Solo, v.31, p.771-780, 2007.

FLORES, R.S.; EUCLIDES, V.P.B.; ABRÃO, M.P.C.; GALBEIRO, S.; DIFANTE, G. dos S.; BARBOSA, R.A. Desempenho animal, produção de forragem e características estruturais dos capins marandu e xaraés submetidos a intensidades de pastejo. Revista Brasileira de Zootecnia, v.37, p.1355-1365, 2008.

FONTOURA JÚNIOR, J.A.S. da; CARVALHO, P.C. de F.; NABINGER, C.; SILVA, J.L.S. da; PINTO, C.E.; CRANCIO, L.A. Produção animal em pastagem nativa submetida ao controle de plantas indesejáveis e a intensidades de pastejo. Ciência Rural, v.37, p.247-252, 2007.

KUSS, F.; RESTLE, J.; BRONDANI, I.L.; PASCOAL, L.L.; MENEZES, L.F.G. de; PAZDIORA, R.D.; FREITAS, L. da S. Características da carcaça de vacas de descarte de diferentes grupos genéticos terminadas em confinamento com distintos pesos. Revista Brasileira de Zootecnia, v.34, p.915-925, 2005.

LOPES, M.L.T.; CARVALHO, P.C. de F.; ANGHINONI, I.; SANTOS, D.T. dos; KUSS, F.; FREITAS, F.K. de; FLORES, J.P.C. Sistema de integração lavoura-pecuária: desempenho e qualidade da carcaça de novilhos superprecoces terminados em pastagem de aveia e azevém manejada sob diferentes alturas. Ciência Rural, v.38, p.178-184, 2008.

LOWMAN, B.G.; SCOTT, N.; SOMERVILlE, S. Condition scoring beef cattle. Edinburgh: East of Scotland College of Agriculture, 1973. 8p.

LUSTOSA, S.B.C. Efeito do pastejo nas propriedades químicas do solo e no rendimento de soja e milho em rotação com pastagem consorciada de inverno no sistema plantio direto. 1998. 84p. Dissertação (Mestrado) - Universidade Federal do Paraná, Curitiba.

MOTT, G.O.; LUCAS, H.L. The design, conduct, and interpretation of grazing trials on cultivated and improved pastures. In: INTERNATIONAL GRASSLAND CONGRESS, 6., 1952, State College. Proceedings. State College: Pennsylvania State College, 1952. p.1380-1385.

POLI, C.H.E.C.; CARVALHO, P.C. de F. Planejamento alimentar de animais: proposta de gerenciamento para o sistema de produção à base de pasto. Pesquisa Agropecuária Gaúcha, v.7, p.145-156, 2001.

PONTES, L. de S.; CARVALHO, P.C. de F.; NABINGER, C.; SOARES, A.B. Fluxo de biomassa em pastagem de azevém anual (Lolium multiflorum Lam.) manejada em diferentes alturas. Revista Brasileira de Zootecnia, v.33, p.529-537, 2004.

QUADROS, F.L.F. Produtividade animal a pasto: manejo e utilização de forrageiras de inverno em terras altas, integrando lavoura do seco e pecuária. In: CICLO DE PALESTRAS EM PRODUÇÃO E MANEJO DE BOVINOS DE CORTE, 4., 1999, Canoas. Anais. Canoas: Ulbra, 1999. p.91-100.

RESTLE, J.; VAZ, F.N. Aspectos quantitativos da carcaça de machos Hereford, inteiros e castrados, abatidos aos quatorze meses. Pesquisa Agropecuária Brasileira, v.32, p.1091-1095, 1997.

SAS INSTITUTE. Statistical analysis system: user's guide. Version 6.08. Cary: SAS Institute, 1997. 846p.

Recebido em 1 de agosto de 2010 e aprovado em 8 de julho de 2011 